\title{
Unusual tomographic findings of complicated necrotizing pancreatitis
}

\author{
Rosa Maria Silveira Sigrista, Samira Ineida Morais Gomes ${ }^{a}$, \\ Daniela Tavares Possagnoloa, Brenda Margatho Ramos Martines ${ }^{b}$
}

Sigrist RMS, Gomes SIM, Possagnolo DT, Martines BMR. Unusual tomographic findings of complicated necrotizing pancreatitis. Autopsy Case Rep [Internet]. 2013; 3(4): 63-8. http://dx.doi.org/10.4322/acr.2013.041

\section{ABSTRACT}

Acute pancreatitis (AP) is a potential life-threatening disease, which originates from inflammatory involvement of the pancreas and surrounding tissues. Serious complications eventuate and treatment is difficult. AP is classified in both interstitial edematous pancreatitis, which occurs in $70-80 \%$ of patients, and necrotizing pancreatitis, which occurs in $20-30 \%$ of patients. Diagnosis is based on the presence of two of the following criteria: abdominal pain, increased serum determination of amylase and/or lipase more than three times the reference value, and characteristic tomographic findings. Among the latter, there is the pancreatic and surrounding tissue damage as well as that related to distant organ involvement. This case report shows the fatal case of a male patient with a history of heavy alcoholic abuse admitted with the diagnosis of necrotizing pancreatitis. The authors call attention to the unusual tomographic findings; namely, a huge duodenal hematoma and a large hemoperitoneum, ischemic involvement of the spleen and kidneys, as well as pancreatic and peripancreatic necrosis.

Keywords: Pancreatitis, Acute Necrotizing; Hemoperitoneum; Duodenal Diseases.

\section{INTRODUCTION}

The incidence of acute pancreatitis (AP) ranges from 50 to 80 cases per year per 100,000 inhabitants in the United States and around 20 cases per 100,000 inhabitants in Brazil. ${ }^{1}$ Biliary origin accounts for $38 \%$ of all cases mostly associated with micro calculi $(<$ $5 \mathrm{~mm}$ ), and $36 \%$ of cases are associated with alcohol consumption. Other less common causes include drugs (corticosteroids, didanosine and pentamidine, valproic acid, chemotherapy agents, and statins), hypertriglyceridemia, hypercalcemia, pancreatic duct obstruction caused by tumor, biliary parasites, trauma, retrograde endoscopic cholangiopancreatography, viral infections, polyarteritis nodosa, developmental abnormalities, as well as pancreas divisum and annular pancreas. ${ }^{2,3}$

The inflammatory process starts when trypsin, a proteolytic pancreatic enzyme, is inappropriately activated on the pancreas itself, instead of into the duodenum. This enzymatic activation results in glandular autodigestion and triggers an inflammatory cascade. The release of cytokines in the circulation will result in a systemic

\footnotetext{
a Department of Radiology - Instituto do Coração - Faculdade de Medicina - Universidade de São Paulo, São Paulo/SP - Brazil. b Diagnostic Imaging service - Hospital Universitário - Universidade de São Paulo, São Paulo/SP - Brazil.

Copyright $\odot 2013$ Autopsy and Case Reports - This is an Open Access article distributed of terms of the Creative Commons Attribution NonCommercial License (http://creativecommons.org/licenses/by/3.0/) which permits unrestricted non-commercial use, distribution, and reproduction in any medium provided article is properly cited.
} 
inflammatory response syndrome (SIRS). Ischemic damage has been recognized as an important mechanism in the pathogenesis of $\mathrm{AP}$, especially in patients with necrotizing pancreatitis. ${ }^{4,5}$

The diagnosis of AP is based on the presence of two of these three criteria: ${ }^{6}$

a) Clinical presentation: upper abdominal pain usually, vomiting, nausea;

b) Biochemical criteria: increased serum determination of amylase and/or lipase more than three times the reference value;

c) Imaging findings, either ultrasound, computed tomography (CT), or magnetic resonance. ${ }^{7}$

Currently, multidetector computed tomography (MDCT) is the imaging examination of choice to confirm the diagnosis of pancreatitis, to evaluate its extension, and to identify eventual complications. MDCT has sensitivity of $92-95 \%$ and specificity of $98-100 \%$ for the diagnosis of severe pancreatitis. The acute tomographic findings of pancreatitis comprise an increase in pancreatic volume, the blurring of pancreatic outlines, the heterogeneous enhancement of the pancreatic parenchyma after intravenous contrast injection, and the densification of peripancreatic adipose tissue. $^{8}$

According totherevisedAtlantaclassification, ${ }^{9}$ AP may be classified as interstitial edematous pancreatitis and necrotizing pancreatitis. The former accounts for $70-80 \%$ of the cases and may be associated with localized or diffuseenlargement of the pancreas with normal homogeneous enhancement or slightly heterogeneous enhancement of the pancreatic parenchyma related to edema. The peripancreatic and retroperitoneal tissue may be normal or may show mild inflammatory changes with varying amounts of peripancreatic fluid collection. Necrotizing pancreatitis, in turn, accounts for 20$30 \%$ of the cases, and shows two distinct phases. The early phase, which occurs in the first week, is characterized by both pancreatic inflammation with varying degrees of edema/ischemia, necrosis, and liquefaction. The late phase is mostly characterized by increased necrosis, infection, and persistence of organ dysfunction. Parenchymal necrosis is divided on contrasted-enhanced CT into less than $30 \%$ and greater than $30 \% .{ }^{10}$ Other forms of presentation include peripancreatic necrosis alone and pancreatic parenchymal necrosis with peripancreatic necrosis, which is the most common type of presentation. ${ }^{9}$

\section{CASE REPORT}

A 42-year-old man sought emergency medical care complaining of upper abdominal pain accompanied by fever, loss of appetite, postprandial bloating, weakness, and constipation over the last 40 days. More recently, vomiting supervened. His past medical history included hospitalization due to alcoholic pancreatitis 2 years ago, alcoholism (daily ingestion of $100 \mathrm{~g}$ of alcohol for 30 years), smoking, and abuse of marijuana, cocaine, and crack. He had been abstinent for the past 40 days.

On physical examination, he was conscious, pale and dehydrated. His pulse was 108 beats per minute; blood pressure was 176/116 $\mathrm{mmHg}$; axillary temperature was $36.7{ }^{\circ} \mathrm{C}$; and oximetry was $96 \%$ with nasal $\mathrm{O}_{2}$ supplementation. The abdomen was tender in the epigastrium and left hypochondrium where a mass was palpable. The bowel sounds were decreased, and no signs of peritoneal irritation were present. Laboratory findings included a mild anemia, leukocytosis, renal failure (creatinine $7.7 \mathrm{mg} / \mathrm{dL}$; urea $165 \mathrm{mg} / \mathrm{dL}$; and potassium 5.6 $\mathrm{mEq} / \mathrm{L})$, normal bilirubin and hepatic enzymes determination, prolonged prothrombin time (international normalized ratio 2.04) and high serum determination of amylase (1018 U/L), lipase (739 $\mathrm{U} / \mathrm{L})$ and lactic dehydrogenase $(760 \mathrm{U} / \mathrm{L})^{*}$ Imaging examination will be shown in the discussion.

The clinical course was characterized by shock, multiple organ failure, and visceral and intraperitoneal bleeding. Death occurred in the following days despite the support treatment. No surgical treatment could be attempted because of the patient's poor clinical status.

\footnotetext{
* Reference values: urea 5-25 mg/dL; creatinine 0.4-1.3 mg/dL; potassium 3.5-5.0 mEq/L; amylase 20-160 U/L; lipase < $60 \mathrm{U} / \mathrm{L}$; and LDH $120-246 \mathrm{U} / \mathrm{L}$.
} 


\section{DISCUSSION}

Upon arrival at the hospital, the middle-aged patient, who was an alcoholic and already had a diagnosis of pancreatitis, had two of the three criteria for the diagnosis of pancreatitis; ${ }^{9}$ namely, upper abdominal pain, vomiting, nausea, and an amylase determination of $1.018 \mathrm{U} / \mathrm{L}$ (more than three times higher than the reference value in adults). The high serum amylase level is not only a diagnostic requirement, but also a marker of severity. ${ }^{9}$ Unfortunately, on admission the patient already had multiple organ failure, which also characterized the severity of the disease.

According to the revised Atlanta classification, ${ }^{9}$ morphological criteria defined by MDCT should be considered in conjunction with the clinical parameters for better establishing the severity of pancreatitis, for confirming the diagnosis, and for eventually elucidating the etiology. ${ }^{11}$

The attenuation of normal pancreatic parenchyma is around 40-50 Halsfield Units (HU). After contrast administration, the pancreas must have a homogeneous enhancement, achieving an attenuation between 100 and $150 \mathrm{HU}$. If the entire pancreas, or a part of it, does not show this enhancement, or if it is less than $30 \mathrm{HU}$, low perfusion is very likely and necrosis may supervene. ${ }^{12}$

Although contrasted MDCT must be performed in patients with severe AP, it is not recommended to undertake it less than 72 hours after the onset of symptoms if the diagnosis of complications is the major concern, unless unexplained clinical deterioration ensues. ${ }^{7-9} A$ repeat examination should be undertaken if the clinical picture drastically changes, such as the sudden onset of fever, the suspicion of bleeding, or there are signs of sepsis. ${ }^{9}$

Necrosis, a result of thrombosis or damage to pancreatic microcirculation, develops early in the course of severe acute pancreatitis (rarely before 48 hours), and is fully established by 96 hours after the onset of symptoms. ${ }^{3,13}$

In this case report, MDCT was performed on admission concomitantly with a sudden drop in the hematocrit, and repeated when signs of shock were present. The diagnosis of necrotizing pancreatitis was made because of the presence of pancreatic necrosis in more than $30 \%$ of the gland with peripancreatic tissue involvement and the presence of hematic material (Figure 1). This combined type of pancreatic and peripancreatic necrosis occurs in $75 \%$ to $80 \%$ of necrotizing pancreatitis. ${ }^{9}$

Along with the necrotic destruction of the pancreatic parenchyma, MDCT also showed acute necrotic collections, steatonecrosis (Figure 2), and a circumscribed, homogeneous peripancreatic fluid collection with a well-defined capsule posteriorly to the gastric greater curvature. This finding may correspond to a pseudocyst or encapsulated necrosis-a diagnosis often challenging by MDCT.

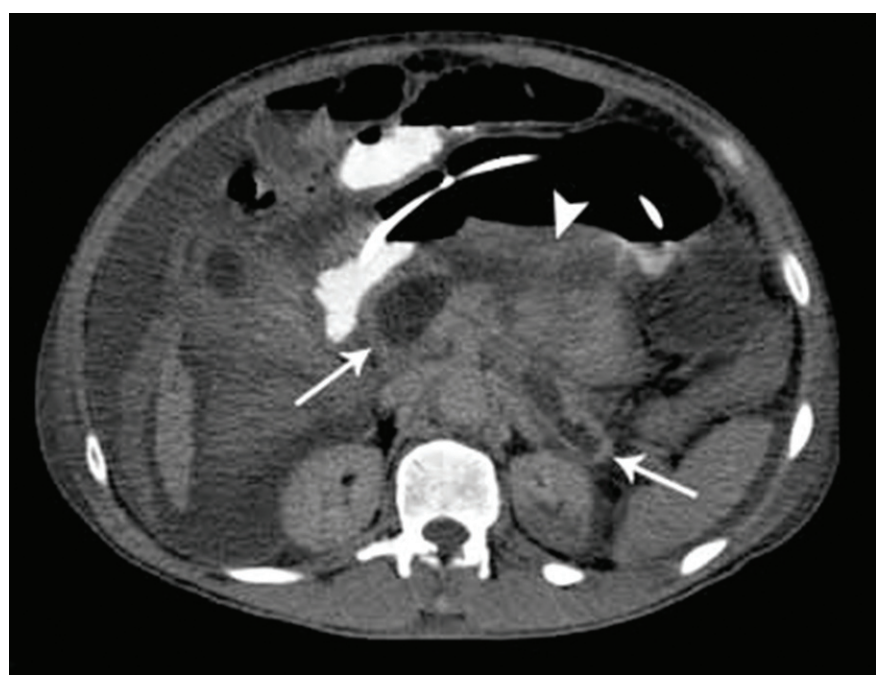

Figure 1 - Multidetector axial computed tomography (CT) of the abdomen, showing necrosis in the pancreatic head and tail (white arrows) and peripancreatic necrosis (arrowhead).

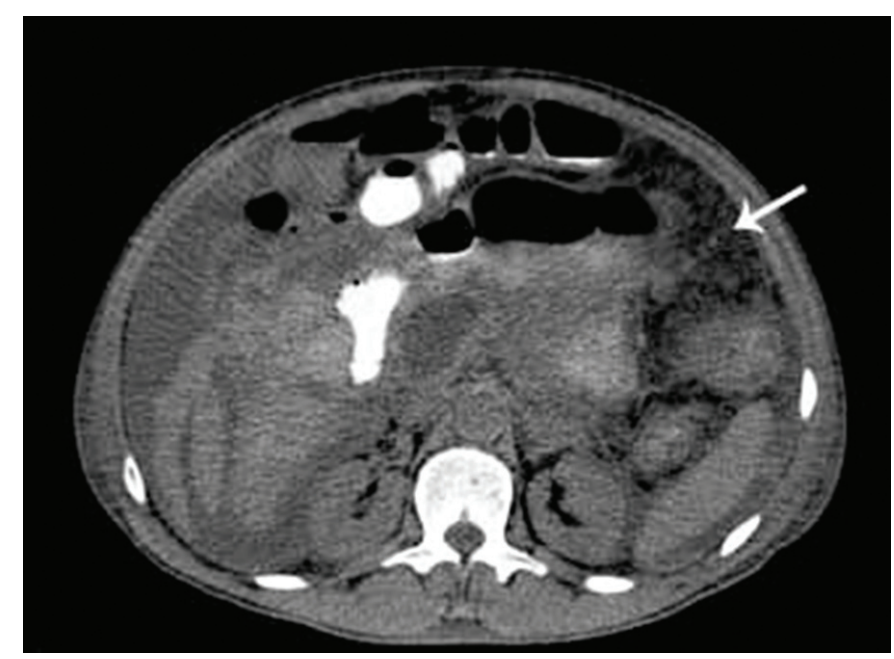

Figure 2 - Multidetector CT of the abdomen, axial section. The white arrow shows an area with steatonecrosis. 
Pseudocysts, extensive inflammation, regional necrosis, and infection may cause erosion in the visceral vessels, with or without the development of pseudoaneurysms, leading to severe bleeding in the gastrointestinal tract, the retroperitoneal space, and the peritoneal cavity. ${ }^{3,14}$ Acute erosion of visceral arteries, although unusual, is a catastrophic complication. Gastrointestinal bleeding or severe intra-abdominal hemorrhage associated with acute pancreatitis is related to a significantly higher risk of death. ${ }^{15,16}$

Another rare complication observed in MDCT in this patient was an intramural duodenal hematoma (Figure 3). Considered a life-threatening complication, intramural duodenal hematoma is most commonly observed after abdominal trauma, endoscopic sclerotherapy, duodenal biopsies, or coagulopathy; however, it may be observed in the course of acute pancreatitis, and is frequently associated with impaired gastric emptying, duodenal perforation, and sepsis. ${ }^{17}$ Few cases of duodenal hematoma secondary to pancreatitis have been reported and its origin may be caused by pancreatic enzyme injury against duodenal vessels. ${ }^{18}$

In this case reported, we also observed a moderate amount of blood adjacent to the celiac trunk vessels and the upper mesenteric artery. We inferred that the pancreatic inflammatory process and necrosis may have contributed to erode these vessels and consequently caused

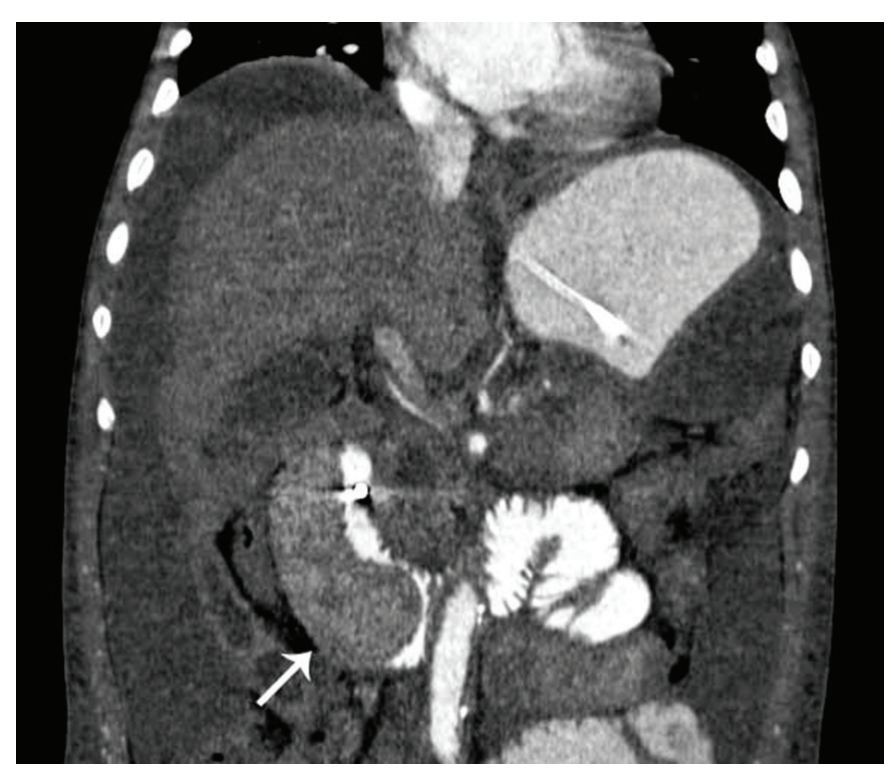

Figure 3-Multidetector CT of the abdomen, coronal reformation, showing tapering of the lumen of the second duodenal portion caused by intramural duodenal hematoma (white arrow). the hemoperitoneum. MDCT has a high sensitivity to detect small amounts of hematic liquid in the peritoneal cavity, as well as evaluate vascular complications. ${ }^{19,20}$ The patient of this case report had a huge hemoperitoneum, and taking into account the magnitude of the drop in hematocrit determination the intraperitoneal bleeding was massive (Figure 4).

The mortality rate among patients with hemoperitoneum seems to be related to the etiology of bleeding and location. In patients with acute or chronic pancreatitis, this complication rate is $60.4 \%$ and $57.1 \%$, respectively. The arteries more involved with mortality are the splenic (20.5\%), the gastroduodenal $(27.9 \%)$, and the upper pancreatoduodenal arteries $(46.1 \%){ }^{14}$

In the case reported here, ischemic complications were found in the kidneys and spleen where hypoattenuating areas were interpreted as infarctions (Figure 5).

Acute renal failure (ARF) is a common complication of severe AP associated with increased morbidity and mortality. The precise mechanism of ARF in patients with severe AP has not been clarified. It involves several factors, such as hypoxia, the release of pancreatic enzymes affecting the renal microcirculation, decreased renal perfusion pressure due to abdominal compartment syndrome, intra-abdominal hypertension, and hypovolemia. Endotoxins and free radicals also play an important role in the physiopathology of severe AP and ARF. ${ }^{21}$

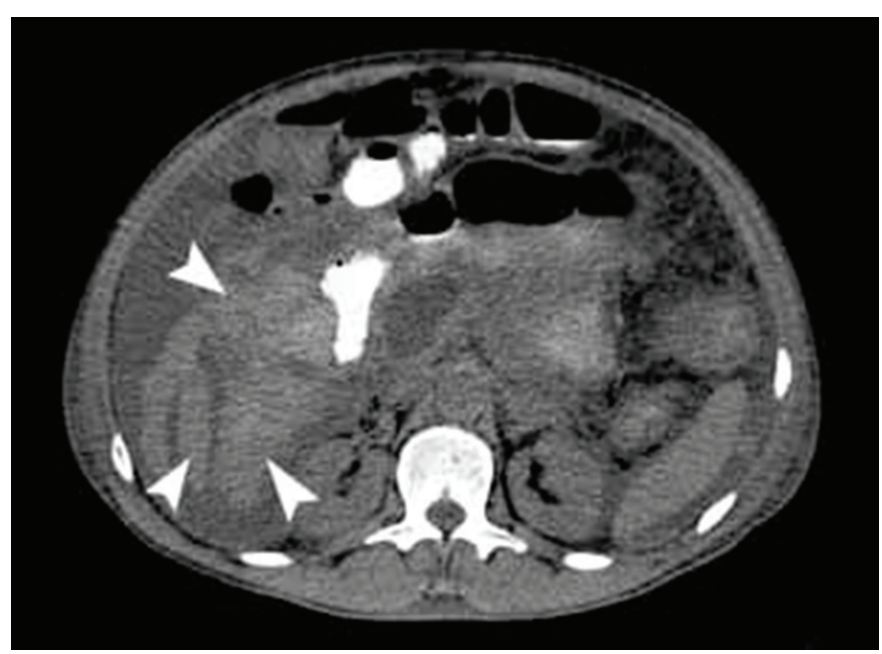

Figure 4 - Axial Multidetector CT of the abdomen. Arrowheads indicate hyperattenuated areas corresponding to free fluid in the abdominal cavity, indicating hemoperitoneum. 


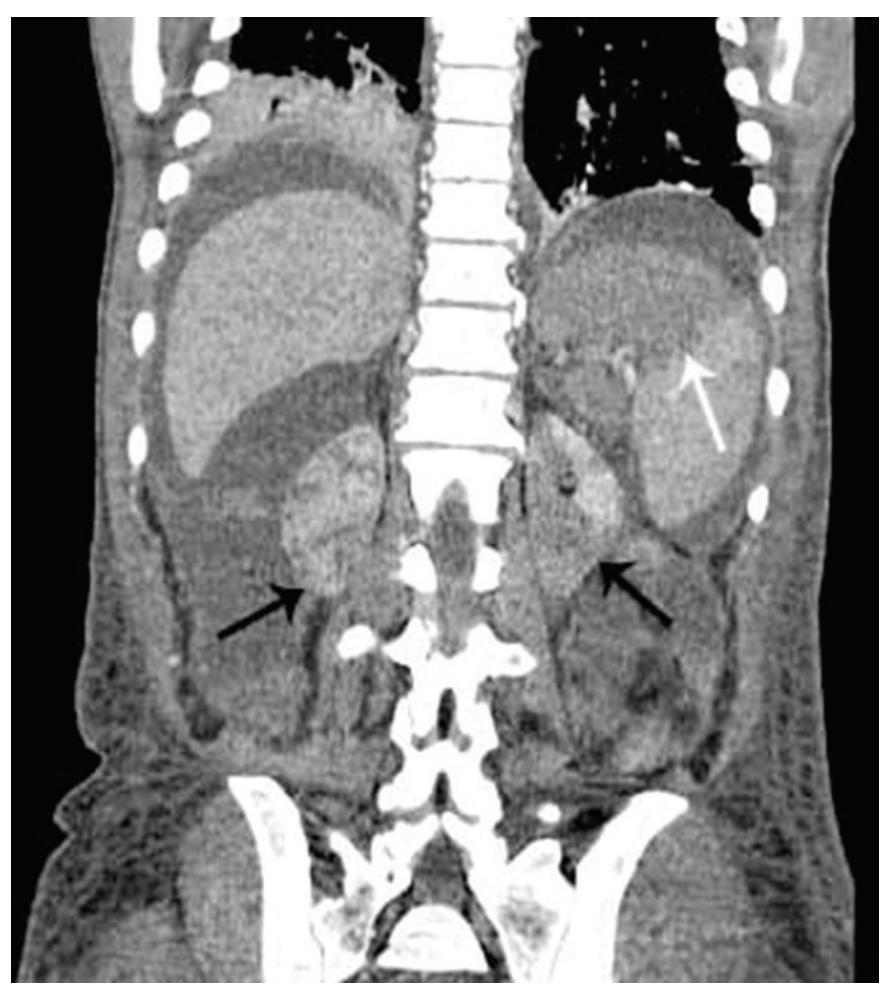

Figure 5 - Multidetector CT of the abdomen, coronal reformation, showing splenic hypodense areas suggestive of splenic infarction (white arrow), showing hypoattenuating areas in both kidneys compatible with renal infarctions (black arrows).

Splenic involvement in AP is rare; however, in this case, we observed hypoattenuating areas permeating the splenic parenchyma (Figure 4). The contiguity between the pancreatic tail and the splenic hilum may constitute a gateway to the inflammatory process. ${ }^{22}$

The liver is another organ that can be affected by AP. In this case, we observed thin perivesicular hypoattenuating areas, which may correspond to perfusion hepatic disorders. The pancreatic inflammatory process extended along the hepatoduodenal gastrohepatic ligament and the portal vein, reaching the Glisson's capsule. Perfusion changes caused by AP usually reach the right liver lobe. Systemic mediators and the local inflammatory process are responsible for this damage..$^{23}$

This patient presented severe complications, some of them rare. We highlight the fact that MDCT was an excellent auxiliary method for all the above mentioned diagnoses, proving to be not only useful for diagnosis, but also crucial for the follow-up of any patient with AP.

\section{REFERENCES}

1. De Campos T, Parreira JG, Utiyama E, Rasslan. Pesquisa nacional sobre condutas na pancreatite aguda. Rev Col Bras Cir. 2008;35(5):304-10. Portuguese. http://dx.doi. org/10.1590/S0100-69912008000500006

2. Sakorafas GH, Tsiotou AG. Etiology and pathogenesis of acute pancreatitis: current concepts.J Clin Gastroenterol. 2000;30(4):343-56. PMid:10875461.

3. Trout AT, Elsayes KM, Ellis JH, Francis RI. Imaging of acute pancreatitis: prognostic value of computed findings. J Comput Assist Tomogr. 2010;34(4):485-95. http://dx.doi. org/10.1097/RCT.0b013e3181d344ca

4. Banks PA, Freeman ML. Practice guidelines in acute pancreatitis. Am J Gastroenterol. 2006;101(10):2379-400. PMid:17032204.

5. Frossard JL, Steer ML, Pastor CM. Acute pancreatitis. Lancet. 2008;371(9607):143-52. PMid:18191686.

6. Sarr MG, Banks PA, Bollen TL, et al. Revision of the Atlanta classification of acute pancreatitis. Gut. 2013;62(1):102-11.

7. Baron T. Managing severe acute pancreatitis. Cleve Clin J Med. 2013;80(6):354-9. PMid:23733900. http://dx.doi. org/10.3949/ccjm.80gr.13001

8. Turner M. Pancreatitis: role of US and CT. Gastrointest Endosc. 2002;56(6 Suppl):S241-5. PMid:12447275.

9. Thoeni R. The Revised Atlanta Classification of Acute Pancreatitis: its importance for the radiologist and Its effect on treatment. Radiology. 2012;262(3):751-64. PMid:22357880. http://dx.doi.org/10.1148/radiol.11110947

10. Bollen TL, Singh VK, Maurer R, et al. Comparative evaluation of the modified CT severity index and CT severity index in assessing severity in acute pancreatitis. AJR Am J Roentgenol. 2011;197(2):386-92. http://dx.doi.org/10.2214/ AJR.09.4025

11. Bharwani N, Patel S, Prabhudesai S, Fotheringham T, Power N. Acute pancreatitis: the role of imaging in diagnosis and management. Clin Radiol. 2011;66(2):164-75. PMid:21216333. http://dx.doi.org/10.1016/j.crad.2010.09.003

12. Balthazar EJ. Acute pancreatitis: assessment of severity with clinical and CT evaluation. Radiology. 2002;223(3):603-13. PMid:12034923.

13. Isenmann R, Buchler M, Uhl W, Malfertheiner $\mathrm{P}$, Martini $M$, Beger HG. Pancreatic necrosis: an early finding in severe acute pancreatitis. Pancreas. 1993;8(3):358-61. PMid:8483878.

14. Flati G, Salvatori F, Porowska B, et al. Severe hemorrhagic complications in pancreatitis. Ann Ital Chir. 1995;66(2):233-7. 
15. Bretagne JF, Heresbach D, Darnault P, et al. Pseudoaneurysm and bleeding psedocysts in chronic pancreatitis: radiological findings and contribution to diagnosis in 8 cases. Gastrointest Radiol. 1990;15(1):9-16. http://dx.doi.org/10.1007/ BF01888725

16. Sand JA, Seppanen SK, Nordback IH. Intracystic hemorrhage in pancreatic pseudocysts: initial experiences of a treatment protocol. Pancreas. 1997;14(2):187-91. http://dx.doi. org/10.1097/00006676-199703000-00012

17. Ma JK, Ng KK, Poon RT, Fan ST. Pancreatic-induced intramural duodenal haematoma. Asian J Surg. 2008 Apr;31(2):83-6. PMid:18490220. http://dx.doi.org/10.1016/ S1015-9584(08)60063-9

18. Bodnar Z, Várvölgyi C, Tóth, J, Sápy P, Kakuk, G. Intramural duodenal hematoma complicating acute necrotizing pancreatitis. Gastrointest Endosc. 2000;52(6):791-3. PMid:11115923.

\section{Conflict of interest: None}

Submitted on: $5^{\text {th }}$ August 2013

Accepted on: $6^{\text {th }}$ December 2013

Correspondence: Departamento de Radiologia Incor - Faculdade de Medicina da USP

Av. Dr. Enéas Carvalho de Aguiar, 44 - Cerqueira César - São Paulo/SP - Brazil CEP: 05403-900 - Phone: +55 (11) 2661-5604

E-mail: rosasigrist@hotmail.com
19. Federle MP, Goldberg HI, Kaiser JA, Moss AA, Jeffrey RB Jr, Mall JC. Evaluation of abdominal trauma by computed tomography. Radiology. 1981;138(3):637-44. PMCid:1306082.

20. Turner, A. The role of US and CT in pancreatitis. Gastrointest Endosc. 2002;56(6 Suppl):S241-5. PMid:12447275.

21. Petejova N, Martinek A. Acute kidney injury following acute pancreatitis: Biomed Pap Med Fac Univ Palacky Olomouc Czech Repub. 2013;157(2):105-13. PMid:23774848. http:// dx.doi.org/10.5507/bp.2013.048

22. Siu T. Percutaneous drainage of spontaneous subcapsular haematoma ofthe spleen complicating chronic pancreatitis. Surgeon. 2004;2(1):52-5. PMid:15570808.

23. Tutcu S, Serter S, Kaya Y, et al. Hepatic perfusion changes in an experimental model of acute pancreatitis: Evaluation by perfusion CT. Eur J Radiol. 2010;75(2):203-6. PMid:19501998. http://dx.doi.org/10.1016/j.ejrad.2009.04.072 